CASE OF ADDISON'S DISEASE; NECROPSY. BY C. CRAWFORD AIIIKEN, M.B. EDIN.

0x Nor. 28th, 1894, I was called to see a farm labourer aged fifty-nine years. He complained of weakness, nausea and romiting, and had been ill for about nine months. His previons health had been very good, and with the exception of a dislocation of the shonlder-joint, sustained through a severe fall five years before, he had never had any serious accident. He gave a satisfactory family history, but two brothers appear to have died from phthisis. His habits as to food and drink were good; his home was comfortable; and his work, though exposing him occasionally to the inclemencies of the weather, was light and wholesome. His wiginal occupation was that of a butcher, but in 1889 he had been obliged to resign it and turn for a livelihood to farm labour. The illness of which he complained commenced insidionsly. The initial symptoms were languor, depression of spirits, and fatigue after exertion, and were first noticed in the previons February. They became gradually more pronounced, and were supplemented in April by attacks of headache, giddiness, palpitation, and shortness of breath. His appetite, moreover, became exceedingly poor, and he began to experience vague pains, shooting and barning in character, in the region of the stomach. He consulted a medical man and was told that he suffered from indigestion. He accordingly had a course of medicinal treatment; but his condition, instead of improving, grew daily worse, and the weakness became at length most distressing. He continued, however, his employment, and throughout July worked hard at the hay harvest. But the severe manual labour and the heat of summer told so disastrously upon his already enfeebled frame that eventually, in the second week of August, be was obliged to give up work and take to bed. His friends noticed that he was looking worn and ill, and tinat his face and hands had a peculiar yellowish discolouration. He placed himself a second time under treatment, but his condition showed not the least amelioration. He began in September to suffer frequently from nausea and vomiting. The nausea, thongh usually worst in the morning, persisted often for an entire day, and prevented him taking a due amount of nourishment; while the vomiting attacks, accompanied as they were by intense retching, left him on each occasion sensibly weaker, and reduced him at last to a condition of extreme prostration. His throat was very sore after the vomit. ing, and occasionally his spatum would be blood -streaked. $\mathrm{He}$ had, moreover, developed latterly a slight cough and become emaciated; but had no diarrhœ $\mathrm{z}$, night-sweating, or hæmoptopis. When I saw bim on Nov. 28th he was utterly exhausted with the recent and severe vomiting. Although of powerful oild and muscular development, he was markedly emaciated, and one could not fail to be struck with the peculiar cachectic anpearance he presented. The cheeks were hollow, the eyes sunken, the lips somewhat cyanosed ; the ocular conjunctivæ were yellowish and slightly injected, while the skin had a distinctly sallow tinge, which on exposed parts, in the kexures of joints, and in the region of the genitals deepened gradally, though decidedly, into shades of walnut-brown, the hands, axillæ, genitals, and back of the neck being the regions most pigmented, while the scalp, front of the chest, abdomen, legs feet, and mucous membrane of the mouth were apparently unaffected. The discolouration varied much in its intensity in different parts, but was of uniform type and uninterrapted by spots or mottling of any kind. The skin was free trom eraption, excess of moisture, and itching; and there was, with the exception of blueness of the lips and faint dnskiness and clubbing at the finger-tips, no cyanosis and no cedema. There were no evidences of acute suffering, but the whole attitude and expression of the patient betokened great mental depression and physical exhaustion. $\mathrm{He}$ lay in a listless, semi-comatose state, sighing and yawning frequently. He bad no appetite, and complained much of thirst, heart. barn, flatnlence, and pyrosis, with dall aching pain in the epigastriam and feelings of distension and weight about the stomach. He bad, moreover, been very sick all the morning, and had vomited all his food a few minutes after taking it, each ejection being accompanied and preceded by intense stomachic pain and retching. Examination of the abdomen thew no light upon the cansation of such symptoms. There was, indeed, some tenderness on pressure in the epigastric and hypochondric regions; but no tumour was anywhere discoverable, and the liver and stomach were not enlarged. The bowels were sluggish and the fæcal matter small in amount and pale almost to chalkiness; but neither that nor the vomited matter contained any blood, and the patient did not suffer from hemorrhoids. There was, however, considerable anæmia. It was unaccompanied by any enlargement of blood glands and was evidently not due to hæmorrhage. The symptoms were headache, giddiness, buzzing in the ears, palpitation, and shortness of breath on exertion. There was a loud hum in the external jugular vein and a systolic murmur in the cardiac pulmonary area. The heart was apparently free from valvular lesion; but the heart sounds, especially the first, were extremely faint. The pulse was regular, moderate in frequency, small in volume, and of low tension. The temperature was subnormal. The urine was clear and straw-coloured, and showed no traces of sugar, albumen, bile, or blood pigments. The patient had a slight cough, with expectoration of scanty, frothy, blood-streaked mucus. The breathing was shallow and the breath sounds almost inaudible. Crepitations, nonconsonating, were audible at the base of each lung, and all over the chest were faint rhonchi, while at the right apex there were a few fine crepitations and a slight prolongation of expiration. There was, however, no dulness or other sign of consolidation. After a careful consideration of the symptoms of the case as a whole, and of the possibility respectively of malignant disease, gastric ulcer, biliary obstruction, chronic phthisis, Bright's disease, and pernicious anæmia, the provisional diagnosis of Addison's disease was made. The prognosis was hopeless, and the treatment, which consisted of milk diet, stimulants, and arsenic, was useless. The patient lingered on for three days, semi-comatose and almost pulseless, and died on the evening of Dec. 1st.

Necropsy on Dec. 4th, 1894. - Patrefaction was just beginning to show itself in green discolouration of the abdomen. Rigidity was present in all the muscles and hypostasis was well marked. The pigmentary changes in the skin of various regions were distinct, more so perhaps than in life. The muscles were much wasted, but there was a fair amount of subcutaneous fat. The heart, which was the first organ examined, was small, pale, and uncontracted, rough and lymph-coated on its epicardiac surface, but inside quite free from endocardiac or valvular disease. The lungs were crepitant throughout and had no morbid excavation or consolidation; but the lower lobes of each lung and the apex of the right were profoundly congested. The stomach was of normal size and contained a little milky food. Its mucous lining was pale, covered with glairy mucus, ecchymosed, and slightly mammillated at the pylorus, but without any signs of ulceration or cicatrices. The intestine, beyond slight congestion of its Peyerian patches and prominence of the solitary follicles, showed nothing abnormal. The spleen was small and shrivelled, and its pulp in a liquid condition; but the liver, gall-bladder, and bile-ducts, with the kidneys and the pancreas, were apparently normal. The adrenals both showed remarkable changes. The right one was, in its lower part, quite hard and calcareons, while the left was represented by a caseous, nodulated, cubical mass two and a balf inches in diameter, which on section showed ronnded cheesy areas of a yellow colour, separated from one another by bands of darker-coloured fibrous tissue. Each supra-renal mass was perfectly circumscribed, but surrounded by a considerable amount of thickened connective tissue, in which many of the nerve fibres connected with the solar plexus were implicated. No change, however, was observed in the surrounding ganglia or in neighbouring lymph glands. Barnsley.

\section{A CASE OF RUPTURE OF THE UTERUS OCCURRING AT THE FIRST ONSET OF LABOUR.}

BY WM. HARRIS BEST, L.S.A. LOND.

As rupture of the uteras early in labour is of very rare occurrence, I think the following case should be recorded.

The patient, aged thirty-two, mother of seven children, of good physique and accustomed to work hard in household matters, but always having plenty of good nourishment, was attended in her previous confinement by myself, abont 
eighteen months before the present one. She never had any miscarriage or other symptom of syphilis. I find the following note in my case-book relating to her last confinement: "Long and tedions first and second stages; pelvis roomy; presentation first cranial. Frgot was of decided benefit in arousing uterus to stronger action during second stage. On the fifth day I found on visiting my patient that she was dressed and downstairs, so I immediately ordered her back to bed, where she remained until the tenth day. No ill effects apparently followed this early rising beyond slight increase of discharge. This, her eighth, confinement commenced in the following unusual manner. She and her husband went to bed as nsual about 11 P.M., she feeling perfectly well at the time. Very shortly after they had been in bed she said to her husband, 'I believe my confinement is coming on.' A few minutes after that she said, 'I am sure it is so ; you had better get up at once.' After he had got up she hurried him off, saying it was coming on quickly. As I was not at home when the message arrived my assistant went immediately. On his arrival he found the nurse there, and was told by ber that shortly after the husband had left a smart bæmorrhage had occurred from the vagina; there was ample evidence of this in the condition of the bedclothes near the patient. Bat one pain occurred and was followed by a gush which she thought was the liquor amnii following the sudden rupture of the membranes. The hæmorrhage ceased when the nurse changed her from the right to the left side; continuous pain was from this time felt on the left side of the abdomen. After waiting about three-quarters of an hour, as labour pains did not come on, I was sent for. On my arrival I found the patient had rather an anxious look on her face. The leftsided pain, though not severe, became so if the abdomen was handled or if she was moved or attempted to move herself. She appeared very nervous and upset, so that it was difficult to tell definitely whether the pain was very acute or the tenderness very great, as she cried out as soon as the vulva was touched in making a raginal examination. There was practically no collapse, and the depression was only such as might have been produced by a slight hæmorrhage. Her pulse was fairly good, 80 beats to the minute. The patient appeared very much disturbed at the prospect of being touched or examined. The pain was confined to the left side and was not severe, the patient talking in an ordinary way and not complaining unless she attempted to move. On vaginal examination I at first failed to reach the presenting part or, indeed, the os; on inserting the whole band into the vagina, however, I could get my middle finger inside the os only about one-third of an inch, bat felt nothing definite. Though the patient said she had felt movements of the child shortly before labour I could not hear the foetal heart sounds. Abdominal palpation yielded no definite result as the patient could not bear its being done properly. Nothing definite was thus made out by either examination. The patient now begged to be left alone for a time, and as her pulse remained fairly good and there was but little pain we did so. Neither labour pains nor bæmorrhage cccurred for the next hour; her pulse remained about the same, and she became rather more comfortable. At this stage the case looked like either a placenta prævia or slight accidental hæmorrhage, the pulse keeping good, and the patient not com plaining of feeling faint or exhausted appeared to place concealed hæmorrhage or ruptured uteras out of the question. As at this time the patient's condition appeared to be improving rather than going back I decided not to use any means for bringing on labour, at least for a time, other than plugging the vagina and orifice of the womb, which latter would answer the double purpose of preventing further external hæmorrhage and keep up a slight reflex stimulation on the womb. This

was carefully done with iodoform wool pellets. A few bed for five days only; but after the disappearance of the hours after this the patient did not appear to have altered more urgent symptoms he continued to suffer from diarrbea much. She took nourishment and kept it down; her pulse until the end of July. He was under the treatment of was, however, quicker, her face looked more anxious, and a Dr. J. F. P. McConnell and was quite well by July $23 r d$. feeling of sickness was complained of. Her temperature in On the last day of August, 1894, be began to suffer from the mouth was $101^{\circ} \mathrm{F}$. I now decided to endeavour to fever, his temperature going up to $102^{\circ} \mathrm{F}$. in the epening accelerate labour by resorting to more active measures. No and falling to $996^{\circ}$ in the morning. To get rid of bæmorrhage followed the removal of the plugging. On this fever he went to Darjeeling on Sept. 8th, and returned making a vaginal examination a hard indistinctly fluctuating remained after the bladder was emptied. A Barnes' bag was with difficulty passed through the os, the difficulty not arising rom the rigidity of the os or any malposition of it, but from its great height. Ergot was given by the mouth freely. No real labour pains followed, though about an hour afterwards the bag was found in the vagina and the os readily admitted two 'The next size Barnes' bag was easily passed, and after a time, the os, and a shoulder was found presenting. Without much difficulty, by means of the bipolar method of version, a foot was brought down into the lowest and posterior part of the the foot. The passive condition of the uterusesduring remoral of the child was noticeable. No blood or liquor amnil up tc this time had escaped. A rupture in the anterior aterine wall could now be detected. The placenta, which was found to be quite free in the uterus, was easily brought away, the ergotin were now given, as the patient complained of feeling faint. She quickly revired. The ateras could not be made to contract, though not even an ordinary amount of external æmorrhage occurred. An iodoform and eucalyptus supposipassing left in the upper part of the vagina with its apez Sickness gradually increased, and the patient died thirty-six hours after the birth of the child with symptoms of peritonitis and exhaustion. No post-mortem examination could obtained."

The points worthy of particular notice in this case appear to be (1) the very early stage at which rupture occurred (2) the absence of any other 'exciting canse than the farlty position of the child (no marked anteversion of the uterns symptoms occurring after so grave an accident.

Ilford, Essex.

\section{NOTE ON THE RELATION BETWEEN} DYSENTERY AND LIVER ABSCESS.

BY A. W. D. LEAHY, M.D. DURH., F.R.C.S. FNG., SLRGEON-MAJOR, IYDTAY MEDICAL SERVICE.

Soмe observers have of late gone the length of denying that any connexion exists between dysentery and abscess of the liver. It is possible, therefore, that notes of the following. case may prove of interest to the profession, for I think it abscess in the right lobe of the liver.

A Earopean male, aged twenty-nine years, was attacked by dysentery on Jane 18th, 1894. The actual dysenteric attack was comparatively slight in character, confining him to bis

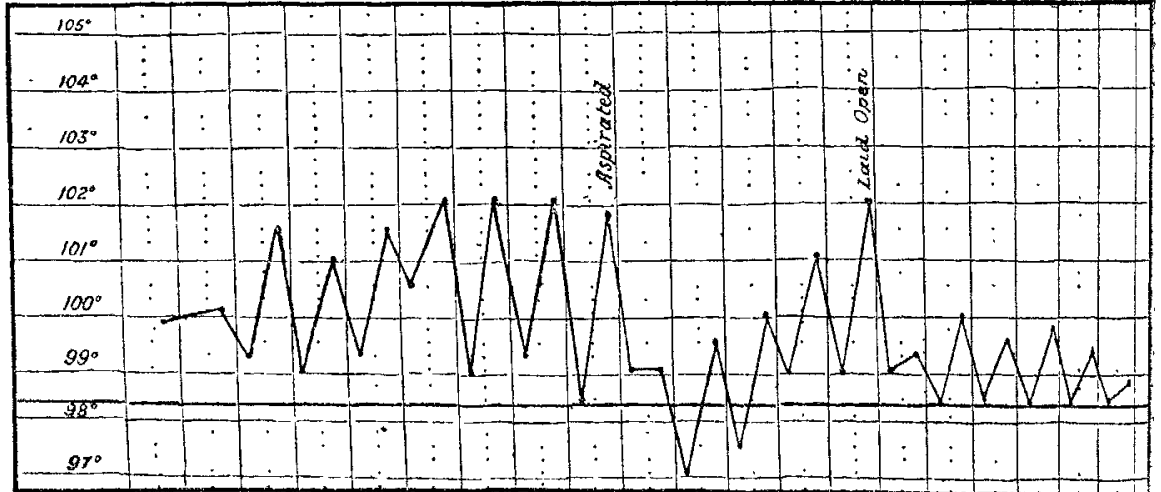
on its removal, three fingers could easily be passed through 